\title{
Exclusivity contracts, insurance and financial market foreclosure ${ }^{1}$
}

\author{
Cédric Argenton Bert Willems \\ CentER \& TILEC, Tilburg University \\ This version: 7 December 2009
}

\begin{abstract}
We study the trade-off between positive effects (risk sharing) and negative effects (exclusion) of exclusivity contracts. We revisit the seminal model of Aghion and Bolton (1987) under risk-aversion and show that although exclusivity contracts induce optimal risksharing, they can be used not only to deter the entry of a more efficient rival on the product market but also to crowd out financial investors willing to insure the buyer at competitive rates. We further show that in a world without financial investors, purely financial bilateral instruments, such as forward contracts, achieve optimal risk sharing without distorting product market outcomes. Thus, there is no room for an insurance defense of exclusivity contracts.
\end{abstract}

JEL codes: D43, D86, K21, L12, L42

Keywords: exclusivity, contracts, monopolization, risk-aversion, risk-sharing, damages

\footnotetext{
1 This paper circulated first as "Exclusivity as inefficient insurance". Both authors thank Jan Boone, Eric van Damme, Richard Meade, Wieland Müller, Jens Prüfer, Yossi Spiegel, and Gijsbert Zwart for insightful comments as well as seminar audiences at Tilburg University, the Research Institute of Industrial Economics in Stockholm, the Netherlands Bureau for Economic Policy Analysis (CPB), the Norges Handelshøyskole (NHH) in Bergen, University of Cologne, University of Bayreuth, and conference participants to the 2008 NAKE research day (Utrecht), INFRADAY 2008 (Berlin), TAI 2008 (Washington, DC), Larsen \& EUI Workshop on "Efficiency, Competition and Long Term Contracts in Electricity Markets" (Florence), CLEEN 2009 (Tilburg) and EARIE 2009 (Ljubljana). The authors are responsible for any mistake or shortcoming.
} 


\section{Introduction}

It is well established that an incumbent firm may use exclusivity contracts to monopolize an industry or deter entry. ${ }^{2}$ Such an anticompetitive practice could be tolerated if it were associated with some sizeable efficiency gains. This paper examines a possible efficiency justification for exclusive dealing: risk-sharing:

Indeed, consumers may prefer the certainty of a constant, known (even if high) contractual price to the vagaries of the spot market. For example, energy-intensive manufacturers may prefer long-term arrangements with incumbent energy suppliers to buying on the spot markets, whose volatility is high (and expected to remain high) given the uncertainty surrounding energy policy. In other terms, they may be risk-averse with respect to electricity prices. $^{3}$

Can the insurance provided by a long-term exclusivity contract be invoked in order to justify its use in the face of its negative impact on competition? This problem is by no means hypothetical. For instance, in recent years, a series of cases involving energy companies were dealt with by European competition authorities. In the Distrigaz decision ${ }^{4}$, the European Commission accepted to close an abuse-of-dominant-position case after the main Belgian gas distributor committed to reduce the gas volumes tied in long-term contracts and to decrease the duration of those contracts so as to make room for entrants. Similar requirements were implemented in decisions Synergen ${ }^{5}$, Repsol ${ }^{6}$ and E.ON/Ruhrgas ${ }^{7}$, out of concern that a dominant firm could use long-term exclusivity contracts to shield a big portion of market sales from competitive pressure. In the French KalibraXE case, an entrant complained that

\footnotetext{
${ }^{2}$ An excellent overview is provided by Bernheim and Whinston (1999).

3 The corporate risk management literature abounds with reasons why firms should hedge their risk. See Chew (2007) for a recent overview. The use of commodity derivatives by firms is well documented, see for instance Nance et al. (1993), Mian (1996), Berkman and Bradbury (1996), Haushalter (2000), Graham and Rogers (2002), and Guay and Kothari (2003). With regards to input purchase behavior, see, e.g., Wolak and Kolstad (1991).

${ }^{4}$ European Commission decision COMP/B-1/37966 - Distrigaz.

${ }^{5}$ European Commission decision COMP/E-3/37732 - Synergen

${ }^{6}$ European Commission decision COMP/B-1/38348 -Repsol

${ }^{7}$ German competition authority (Bundeskartellamt) decision B8-113/03-1 - E.ON Ruhrgas.
} 
the former electricity monopolist was using exclusivity provisions to prevent it from accessing industrial consumers ahead of the liberalization of the sector. In its decision, the French competition authority stressed that any assessment of those clauses could not take place without seriously considering (among other things) the conditions under which those clauses could be terminated, and the economic gains that accrued to customers under the contract, especially those derived from the certainty associated to a fixed price, which may justify its use in the face of its foreclosing effect. ${ }^{8}$

To address this question, we extend the seminal model of Aghion and Bolton (1987) to deal with risk aversion and financial arrangements. We show that exclusivity contracts, although they induce efficient risk-sharing, can be used not only to deter the entry of a more efficient rival on the product market but also to crowd out financial investors willing to insure buyers at competitive rates. Thus, exclusivity clauses can foreclose entry on both the product market and the financial market. We further show that in a world without financial investors exclusivity contracts are welfare-dominated by purely financial bilateral instruments, such as forward contracts, as these do not distort product market outcomes. Thus, we argue that there is no room for an insurance defense of exclusivity contracts.

Our main result arises from the externalities which are present in the contracting process between the incumbent seller and the risk-averse buyer. If the buyer were to buy a forward contract from a financial investor to hedge its spot market risk, he would subsequently find an interest in signing an exclusivity contract with the incumbent in order to extract rent from this financial investor. Indeed, by signing a contract that forecloses entry, the buyer can ensure that the product price will remain high and thus forces the financial investor to be true to his promise of insuring the buyer against adverse spot market outcomes. Because this moral hazard problem is anticipated by financial investors, the market for financial instruments does not develop. As a result, the incumbent's behavior is not constrained by any competitive pressure and exclusivity contracts end up being used so as to extract rents from the entrant and from the main buyer.

\footnotetext{
8 See Conseil de la concurrence, Decision 07-MC-01, especially recitals 48 and 50.
} 
Our model relates to several strands of literature. A first line of research examines socially harmful instances of foreclosure..$^{9}$ When it comes to entry deterrence through the use of exclusivity contracts, two theories stand out of the literature, one being associated to Aghion and Bolton (1987), the other to the "naked exclusion" scenario put forth by Rasmusen, Ramseyer and Wiley (1991) and Segal and Whinston (2000a). ${ }^{10}$ We contribute to the first theory by showing that exclusivity contracts can hinder the development of financial markets in addition to foreclosing efficient rivals on the product market.

A second line describes the gains in efficiency associated with exclusivity contracts. They could arise from promoting relation-specific investments by solving the hold-up problem (e.g. de Meza and Selvaggi, 2007), reducing intra-brand or inter-brand competition (e.g. Mathewson and Winter, 1984; Besanko and Perry, 1993), or fostering efficient product selection (Yehezkel, 2008). As Rey and Tirole (1986), we examine how vertical restraints affect risk sharing, although in an environment where information is symmetric between buyers and sellers.

There are few contributions studying the possible trade-off between efficiency gains and exclusionary effects. In contrast with our paper they all focus on investment decisions. Spiegel (1994) shows that in a modified version of the Aghion and Bolton model, liquidated damages remain excessive and continue to serve as a barrier to entry even in the presence of relation-specific investment, but may nonetheless have an overall positive on welfare. Spier and Whinston (1995) further expand the models by allowing for ex post renegotiation of the exclusivity contract and looking at legal remedies. Fumagalli, Motta and Rønde (2007) also explore investment decisions by building upon Segal and Whinston (2000b), rather than Aghion and Bolton (1987).

A fourth line of research studies the impact of firms' financial positions on product market competition. Firms can use financial contracts as a commitment device to affect the spot market equilibrium. The precise strategy depends on the type of competition. If oligopolists

\footnotetext{
${ }^{9}$ Rey and Tirole (2007) provide an excellent review.

10 In those latter models, an incumbent firm exploits contracting externalities among several customers and prevents a potential entrant from reaching the minimum viable scale. See Argenton (2008) for a review of recent developments.
} 
compete à la Cournot, then they will sell forward contracts to compete more aggressively in the market, which increases their market share at the expense of the other participants (Allaz and Vila, 1993). Willems (2005) shows that those results also hold for option contracts. On the other hand, if oligopolists compete à la Bertrand, then they have an incentive to buy forward contracts, and commit to being less aggressive (Mahenc and Salanié, 2004). The main result of this literature is that firms that hedge themselves by signing (long-term) contracts behave more competitively in the spot market. Willems and De Corte (2008) therefore argue that governments should regulate the risk exposure of (electricity) firms so as to give producers (retailers) an incentive to buy (sell) more forward contracts. This literature neglects the effects of long term contracts on entry incentives and takes the number of existing firms as given. In contrast, our paper studies the entry effect and examines whether the market for derivatives will develop in the first place when firms have market power in the product market.

The structure of this paper is as follows. In Section 2, we present a model characterized by the presence of financial investors who could provide a risk-averse buyer with a hedge against spot price volatility. In section 3 we characterize the equilibrium of this model in various contracting environments. Section 4 discusses the welfare and policy implications, and Section 5 concludes.

\section{Model}

We extend the Aghion and Bolton (1987) model by introducing risk-aversion on the part of the buyer ${ }^{11}$ and by allowing financial investors to offer insurance to the buyer. We study three scenarios corresponding to various contractual relationships between the incumbent and the buyer. In the first scenario no contract can be signed between the two. In the second scenario the incumbent can offer an exclusive contract, as in the original model. In the third scenario the incumbent can offer a standard financial (forward) contract.

Next to those innovations, two additional modifications of the original model are introduced. First, we assume that there is a very small "fringe buyer" that does not sign a long-term contract with the incumbent. This fringe buyer is introduced to obtain a unique

${ }^{11}$ In Section 4.4, we discuss the case where the incumbent seller is risk-averse as well. 
spot price in the case when the incumbent seller and the main buyer sign a forward contract and are therefore perfectly hedged against variations in the spot market price. Without it, the incumbent firm would be indifferent to the market outcome and there would be no meaningful competition between the incumbent and the entrant. Second, we assume that the entrant incurs a small entry cost, which makes it unprofitable for the entrant to enter the market if it can only supply fringe consumers.

Those two modifications preserve the spirit of the original Aghion and Bolton (1987) model in which the entrant could not make any profit in case the (main) buyer did not buy from her.

\subsection{Set-up of the game}

In our model there are five types of players: the main buyer, the fringe buyer, the incumbent, the entrant, and the financial investors.

The main buyer buys one or zero unit of the good. His reservation price for the good is equal to 1 . The main buyer is risk-averse and his expected utility of consuming 1 unit of the good is equal to $V=E[U(1-p)]$, where expectations are taken over the different states of the world, $p$ is the price faced by the buyer in a specific state, and $U()$ the von NeumannMorgenstern utility function $\left(U^{\prime}>0\right.$ and $\left.U^{\prime \prime} \leq 0\right)$, which we normalize by imposing $U(0)=0$.

Next to the main buyer there is a small, risk-neutral fringe buyer who wants to buy $\varepsilon$ units of the good. His expected utility of consuming $\varepsilon$ units is equal to $E[\varepsilon \cdot(1-p)]$.

The incumbent producer is risk-neutral and has a production cost $c_{I}<1$. He seeks to maximize expected profit.

The entrant producer is also risk-neutral and has a production cost $c_{E}$ which is drawn from the uniform distribution over $[0,1]$. The entrant incurs a small entry cost $K>\varepsilon$. This entry cost guarantees that the entrant will not enter the market if she can only sell to the fringe buyer, as the profit she can then make, $\varepsilon\left(p-c_{E}\right)$, will always be smaller than the entry cost since $p \leq 1$ and $c_{E} \geq 0$. We denote by $k \equiv \frac{K}{1+\varepsilon}$ the average fixed cost of the entrant. The entrant strives to maximize expected profit. 
There are two financial investors, who are risk-neutral and maximize expected profit from selling forward contracts.

Uncertainty about the entrant's cost $c_{E}$ is the only source of uncertainty in our model. ${ }^{12}$

The game consists of 6 stages. In stage 1 financial investors compete à la Bertrand for the sale of a forward contract to the main buyer. A forward contract stipulates that the buyer agrees to pay the seller the difference between the forward price, $\varphi$, set in the contract, and the spot market price, $p$. In effect, the buyer of the contract is certain to procure the good at price $\varphi$. Bertrand competition at this stage consists for financial investors in posting a forward price $\varphi$ and being committed to honor the corresponding contract upon acceptance by the main buyer.

In stage 2, the main buyer decides whether he buys a forward contract from one of the financial investors.

In stage 3 after observing the financial position of the main buyer, the incumbent makes him a take-it-or-leave-it offer. This offer can be of three types, depending on the scenario chosen. In the first scenario, the offer consists in not entering into any contractual relationship (no contract). In the second scenario, the offer consists in an exclusivity contract as in Aghion and Bolton (1987) where the buyer ex-ante agrees to pay price $P$ to the incumbent for acquiring one unit or pay penalty $P_{0}$ if he breaches the contract. In the third scenario, the offer consists in a forward contract, according to which the main buyer promises to pay the incumbent the difference between the forward price, $f$, set in the contract, and the spot market price, $p$.

In stage 4 of the game, the main buyer decides whether he accepts the offer of the incumbent or not. ${ }^{13}$

In stage 5 the entrant and all other players in the game learn about $c_{E}$. The entrant decides whether she enters the market and incurs the entry cost.

${ }^{12}$ We solve for pure-strategy equilibria. Hence, there is no additional, 'strategic' source of risk in the model.

${ }^{13}$ This is of course inconsequential in the scenario where the incumbent offers no contract. 
In stage 6, Bertrand competition takes place in the spot market. Active firms post bids. They are committed to serve all demand addressed to them at their posted price.

\subsection{Efficiency}

We now characterize efficient market outcomes. For efficiency three dimensions matter: (i) allocative efficiency, (ii) productive efficiency, and (iii) risk sharing. First, as the production costs are always lower than consumers' willingness to pay, total production should be equal to $1+\varepsilon$ units.

Second, the entrant enters the market only when she has such a production cost advantage vis-à-vis the incumbent as to outweigh her entry cost. Hence, entry should occur as long as the average total cost of the entrant $\left(\frac{c_{E}(1+\varepsilon)+K}{1+\varepsilon}=c_{E}+k\right)$ is smaller than the average production cost of the incumbent, $c_{I}$. In an efficient market, the probability of entry is thus equal to $\operatorname{Prob}\left(c_{E}+k<c_{I}\right)=c_{I}-k$.

Third, because the main buyer is risk-averse and other players are risk-neutral, the main buyer should get full insurance, be it from the main buyer or financial investors. This implies that the main buyer should pay the same price, net of financial transfers, in all contingencies.

\section{Analysis}

We now take the three scenarios of interest (no contract, exclusivity contract, bilateral forward contract between the incumbent and the main buyer) in order and solve for subgame-perfect equilibrium.

\subsection{No contract}

In the first scenario, the incumbent cannot enter into a contractual relationship with the main buyer. Suppose first that the latter has not bought any forward contract from financial investors. Following the entrant's decision to enter the market, Bertrand competition determines the spot market price in stage 6 . Thus, the equilibrium market price is given by

$$
p=\max \left\{c_{I}, c_{E}\right\}
$$


and buyers buy from the lowest-cost firm. In case the entrant decides not to enter, the incumbent will charge buyers their reservation price and the spot market price will be equal to 1.

In stage 5, the entrant will enter as long as she expects to obtain a positive profit.

$$
\left(c_{I}-c_{E}\right)(1+\varepsilon)-K \geq 0 .
$$

The profit she makes by selling $1+\varepsilon$ units at price $c_{I}$, should outweigh the entry cost. When $c_{E}>c_{I}-k$, the entrant chooses not to enter, for she would not make enough sales to cover the entry cost. Entry decisions are efficient, the probability of entry being given by

$$
\phi^{N C}=\operatorname{Prob}\left(c_{E}+k<c_{I}\right)=c_{I}-k,
$$

where superscript NC stands for 'no contract'. The main buyer derives a surplus only when entry occurs, so that his expected utility $V$ is

$$
V^{N C}=\left(c_{I}-k\right) U\left(1-c_{I}\right)
$$

Consider now the case where the main buyer has bought a forward contract $\varphi$ from financial investors in stage 2. (All variables in that case will be ornate with a tilde.) In stage 6, firms compete for the patronage of the fringe buyer. The spot market price does not depend on the financial position of the main buyer and is still given by equation (1). Entry is still as in equation (3).

The main buyer is perfectly insured and enjoys utility $U(1-\varphi)$, independently of the entry decision of the entrant:

$$
\widetilde{V}^{N C}=U(1-\varphi)
$$

In the financial market, investors compete à la Bertrand. In expectation they will make zero profit and set the forward price equal to the expected payment they will make $\varphi=\phi^{N C} \cdot c_{I}+\left(1-\phi^{N C}\right) \cdot 1$. Hence, given efficient entry, the forward price in stage 1 will be equal to:

$$
\varphi=1-\left(c_{I}-k\right) \cdot\left(1-c_{I}\right)
$$


The main buyer will buy such a contract in stage 2 as it will allow him to reduce uncertainty. Indeed, his surplus is larger when he buys a forward contract than when he doesn't:

$$
\widetilde{V}^{N C}=U\left[\left(c_{I}-k\right) \cdot\left(1-c_{I}\right)\right]>\left(c_{I}-k\right) \cdot U\left(1-c_{I}\right)=V^{N C} .
$$

This inequality follows from Jensen's inequality.

\subsection{Exclusivity contract}

In the second scenario the incumbent is allowed to offer an exclusivity contract to the main buyer in stage 3 .

Suppose that the main buyer has bought a forward contract with forward price $\varphi$ from financial investors and agreed to an exclusivity contract $\left(P, P_{0}\right)$ with the incumbent. Upon entry, Bertrand competition in the spot market takes place in stage 6 of the game. The entrant and the incumbent post prices $p_{I}$ and $p_{E}$. The fringe buyer buys its good from the producer with the lowest price at spot market price $p=\min \left\{p_{E}, p_{I}\right\}$.

The main buyer will procure the good from the incumbent and pay the contractual price $P$, or breach the contract, pay a penalty $P_{0}$ and buy the good on the spot market at spot market price $p$. The utility of the main buyer is equal to $U[1-P-(\varphi-p)]$ if he does not breach the contract, and $U\left(1-p-P_{0}-(\varphi-p)\right)$ if he decides to breach. The main buyer will breach only if the gains from breaching outweigh the penalty, that is, only if $p \leq P-P_{0}$.

The market equilibrium thus depends upon the exclusivity contract $\left(P, P_{0}\right)$ signed between the main buyer and the incumbent and the production cost of the incumbent $c_{I}$.

$$
p=\min \left\{c_{I}, P-P_{0}\right\}
$$

As in the original Aghion-Bolton model, entry takes place when $c_{E}<p-k$. Since $c_{E}$ is uniformly distributed, the probability of entry is given by

$$
\tilde{\phi}^{E C}=\min \left\{c_{I}, P-P_{0}\right\}-k
$$


where superscript EC stands for 'exclusivity contract'. Hence, the key externality in this contracting model is that by its choice of $P$ and $P_{0}$, the contracting pair can affect the entry decision of the potential entrant.

At stage 3, the incumbent chooses $P$ and $P_{0}$ to maximize expected profit subject to the participation constraint of the main buyer (i), the post-entry market price (ii), and the entry decision of the entrant (iii).

$$
\begin{aligned}
& \max _{P, P_{0}} \quad \tilde{\phi}^{E C} P_{0}+\left(1-\tilde{\phi}^{E C}\right)\left(P-c_{I}\right)+\left(1-\tilde{\phi}^{E C}\right)\left(1-c_{I}\right) \varepsilon \\
& \text { s.t. } \\
& \text { (i) } \tilde{\phi}^{E C} U(1-P-(\varphi-p))+\left(1-\tilde{\phi}^{E C}\right) U(1-P-(\varphi-1)) \geq U(1-\varphi) \\
& \text { (ii) } p=\min \left\{c_{I}, P-P_{0}\right\} \\
& \text { (iii) } \tilde{\phi}^{E C}=p-k \\
& \text { (iv) } 0 \leq \tilde{\phi}^{E C} \leq 1
\end{aligned}
$$

We are now in the position to assert our first result: the incumbent will choose a corner solution at which entry does not occur at all and the contractual price is equal to one.

Proposition 1. If the main buyer has earlier signed a forward contract with a financial investor, then the incumbent will offer an exclusivity contract such that

$$
\tilde{\phi}^{E C}=0, p=P=1, P_{0}=1-k .
$$

Proof. Relax optimization program (9) by assuming that the main buyer is risk-neutral $(U(x)=x)$ and replace equation (ii) with the equivalent constraints $p \leq c_{I}(v)$ and $p \leq P-P_{0}$ (vi). Under risk neutrality and substituting (iii), the participation constraint simplifies to

$$
1-P \geq\left(1-\tilde{\phi}^{E C}-k\right) \tilde{\phi}^{E C}
$$

In the optimum, this participation constraint is binding as $P$ is a pure transfer between the main buyer and the incumbent. Equation (vi) is also binding, as the objective could otherwise be increased by increasing $P_{0}$ without affecting any other constraint. Substituting (vi), (v) and (10) into the objective function, the incumbent maximizes 


$$
\begin{gathered}
\max _{0 \leq \tilde{\phi}^{E C} \leq 1} \underbrace{(1+\varepsilon)\left(1-c_{I}\right)}_{\text {(1) No-entry profit }}+\underbrace{\tilde{\phi}^{E C}\left(c_{I}-k-\tilde{\phi}^{E C}\right)}_{\text {(2) Rent from entrant }} \\
-\underbrace{\left(1-\tilde{\phi}^{E C}-k\right) \tilde{\phi}^{E C}-\underbrace{\tilde{\phi}^{E C} \varepsilon\left(1-c_{I}\right)}_{\begin{array}{c}
\text { (4) Profit Loss On Fringe } \\
\text { Upon Entry }
\end{array}}}_{\begin{array}{c}
\text { (3) Compensation } \\
\text { of buyer }
\end{array}}
\end{gathered}
$$

This is a well-behaved, convex maximization problem admitting a unique solution. The derivative of the objective function with respect to $\tilde{\phi}^{E C}$ is negative everywhere since $c_{I}<1$ by assumption, establishing the existence of a corner solution $\tilde{\phi}^{E C}=0$. Hence, from constraint (10), $P=1$. and from (ii) and (iii), $P_{0}=1-k$.

In the case where the buyer is risk-averse, this contract continues to be optimal. Indeed, the participation constraint in the original program (9) gets only tighter when the buyer is risk-averse. Hence, the incumbent can never achieve a higher level of profit than under risk-neutrality. In addition, the solution specified in (10) is not risky for the main buyer. Hence, it still satisfies the participation constraint

As can be seen from equation Error! Reference source not found.(10), ignoring the fringe buyer, the profit of the incumbent consist of three parts: (1) the no-entry profit; (2) rent that can be extracted from the entrant upon entry; and (3) a compensation to the buyer for the loss in revenue on its financial contract. The two first terms make up for the total joint profit of the contracting pair, while the third is the amount of money that must be rebated by the incumbent to the main buyer in order to induce him to accept the contract.

It is as if the incumbent always served the buyer and charged price 1 as a result of monopoly power (part 1). Yet, when entry occurs, the incumbent is able to procure the good from the entrant at price $\tilde{\phi}^{E C}$ instead of producing it himself at higher cost $c_{I}$. It is then as if the contracting pair had monopsony power vis-à-vis the entrant and faced the usual monopsony trade-off between price and quantity (part 2). In addition, entry affects the gains the buyer makes on its forward contract. Instead of benefiting from insurance when the entrant stays out (and the price is one), the main buyer receives less money from the financial investor when entry occurs (and the price is $\tilde{\phi}^{E C}$ instead). He must then be compensated $\mathrm{f}$ in order to be willing to accept the contract. (part 3). As the compensation the incumbent needs to pay 
to the buyer in case of entry is larger than the rent he could extract from the entrant, he will fully exclude the entrant.

Proceeding with backward induction, in stage 1, financial investors behave competitively as a result of Bertrand competition. They will therefore offer a forward contract making zero expected profit. If the incumbent is allowed subsequently to offer an exclusivity contract, then anticipating (10), the forward price $\varphi$ at which investors will be willing to supply insurance will be equal to one $(\varphi=1)$.

In stage 2, the main buyer will buy a forward contract whenever his utility of buying is larger than the utility he receives without insurance contract, that is:

$$
U(1-\varphi)>\left(c_{I}-k\right) \cdot U\left(1-c_{I}\right)
$$

Since financial investors only offer a contract with forward price equal to 1 , the main buyer is not interested in buying. In effect, the possibility for the incumbent to offer an exclusivity contract after the closure of the financial market destroys the possibility of insurance arrangements between financial investors and the main buyer.

Thus, on the equilibrium path, the incumbent faces the same trade-off as in the original Aghion and Bolton (1987) model in stage 3. He chooses $P$ and $P_{0}$ so as to maximize expected profits, taking into account the participation constraint of the main buyer (i) and the entry decision of the entrant (ii):

$$
\begin{aligned}
& \max _{P, P_{0}} \quad \phi^{E C} P_{0}+\left(1-\phi^{E C}\right)\left(P-c_{I}\right)+\left(1-\phi^{E C}\right)\left(1-c_{I}\right) \varepsilon \\
& \text { s.t. } \\
& \text { (i) } \quad U(1-P) \geq\left(c_{I}-k\right) U\left(1-c_{I}\right) \\
& \text { (ii) } \phi^{E C}=\min \left\{c_{I}, P-P_{0}\right\}-k
\end{aligned}
$$

Upon entry, the incumbent expects the main buyer to breach and pay penalty $P_{0}$. Conversely, if the entrant stays out, the contract will be honored: the main buyer will get the good at contractual price $P$, while all surplus will be extracted from the fringe buyer by posting price 1 . 
Proposition 2. If the main buyer has not previously signed a forward contract with a financial investor, then the incumbent will offer an exclusivity contract $\left(P, P_{0}\right)$ such that

$$
\begin{aligned}
& U(1-P)=\left(c_{I}-k\right) U\left(1-c_{I}\right) \\
& P-P_{0}=\frac{(1+\varepsilon) c_{I}-\varepsilon+k}{2} .
\end{aligned}
$$

Proof. Consider program (12). If $P-P_{0} \geq c_{I}$, then the contract will not affect the probability of entry and $P_{0}$ can be increased. So, at the optimum $P_{0}=P-\phi^{E C}-k$. As $P$ is a transfer from the main buyer to the incumbent, the participation constraint (i) will bind. The program can then be rewritten as follows:

$$
\begin{aligned}
& \max _{0 \leq \phi^{E C} \leq 1} \underbrace{(1+\varepsilon)\left(1-c_{I}\right)}_{\begin{array}{c}
\text { (1) No Entry } \\
\text { Profit }
\end{array}}+\underbrace{\phi^{E C}\left(c_{I}-\phi^{E C}-k\right)}_{\text {(2) Rent From Entrant }}-\underbrace{W}_{\begin{array}{c}
\text { (3) } \\
\text { Compensation } \\
\text { of buyer }
\end{array}}-\underbrace{\phi^{E C} \varepsilon\left(1-c_{I}\right)}_{\begin{array}{c}
\text { (4) Profit Loss } \\
\text { On Fringe } \\
\text { Upon Entry }
\end{array}} \\
& \text { where } U(W)=\left(c_{I}-k\right) U\left(1-c_{I}\right)
\end{aligned}
$$

This is well-behaved convex program with a unique solution. Simple differentiation delivers the optimal value for $\phi^{E C}$. It is easily verified that it lies between 0 and 1 . Constraints (i) and (ii) then characterize $P$ and $P_{0}$.

Ignoring the fringe player, the profit of the incumbent again consists of three parts: (1) the joint profit of the contracting pair in the absence of entry; (2) rent that can be extracted from the entrant by manipulating the entry decision; and (3) a compensation that the incumbent needs to leave to the buyer in order to induce him to accept the contract.

It is again as if the incumbent faced a monopsony problem vis-à-vis the entrant under the participation constraint of the main buyer. Yet, this time the incumbent insures the main buyer against variation in the spot market price. So, the exclusivity contract allows the incumbent to capture the gains from insuring the main buyer. Indeed, the incumbent only needs to compensate the main buyer for the certainty equivalent $W$ of the lottery promising $1-c_{I}$ with probability $c_{I}-k$ and zero otherwise. As can be easily seen, when the entrant becomes more risk averse, the certainty equivalent decreases, and the incumbent increases its profits. 


\subsection{Financial contract}

In the third scenario the incumbent offers the main buyer a forward contract with forward price $f$.

Assume first that the main buyer did not buy a forward contract from financial investors in stage 2 but bought one from the incumbent in stage 4 . Suppose that the entrant has decided to enter the market. In the pricing subgame, both the incumbent and the main buyer are perfectly hedged against the variations in the spot market price: they have already agreed to transact at price $f$. Competition takes place only for selling to the fringe buyer. Both producers compete à la Bertrand and in equilibrium they post the same price $p_{I}=p_{E}=\max \left\{c_{I}, c_{E}\right\}$, which determines the spot market price, $p$. Buyers buy from the firm with the lowest marginal cost.

The entrant will enter only if her own marginal cost is small enough to allow her to make positive sales and cover the entry cost, so that the probability of entry is

$$
\phi^{F C}=c_{I}-k
$$

In case the entrant stays out, then the incumbent will post a price $p_{I}$ equal to 1 . He will then extract all surplus from the fringe buyer. By contrast, the forward contract caps the net revenue to be made on the main buyer to $f$.

In stage 3, the incumbent will thus offer then main buyer a contract solving

$$
\begin{array}{ll}
\max _{f} & \phi^{F C}\left(f-c_{I}\right)+\left(1-\phi^{F C}\right)\left[\left(f-c_{I}\right)+\varepsilon\left(1-c_{I}\right)\right] \\
\text { s.t. } & \\
\text { (i) } & \phi^{F C}=c_{I}-k \\
\text { (ii) } & U(1-f) \geq\left(c_{I}-k\right) U\left(1-c_{I}\right)
\end{array}
$$

Observe that there is nothing that the incumbent can do to affect entry. The program thus boils down to extracting as much surplus as possible from the main buyer through the forward price by holding him to his reservation utility level:

$$
V^{F C}=V^{N C}=\left(c_{I}-k\right) U\left(1-c_{I}\right)
$$

Suppose now that the main buyer has bought one forward contract from the incumbent at forward price $f$ and one forward contract from a financial investor at forward price $\varphi$. 
The profit of the main buyer is equal to $U\left(1-p_{M B}-(\varphi-p)-(f-p)\right)$ where $p$ is the spot market price and $p_{M B}$, the price at which the main buyer transacts. If the main buyer cannot affect the spot price by buying at a higher price himself, then he has an incentive to buy at the lowest possible price and $p_{M B}=p$. Hence, upon entry the price in the spot market is equal to the standard Bertrand outcome and the buyers buy from the firm with the lowest cost.

In stage 5, the entrant will enter as long as it makes a positive profit in the spot market. Since the contractual arrangements do not affect the spot market outcomes, we have efficient entry happening with probability:

$$
\tilde{\phi}^{F C}=c_{I}-k
$$

In stage 3, the incumbent maximizes its profit by selecting the price at which it will offer a forward contract to the main buyer. The incumbent will only be willing to sell a forward contract to the main buyer if, in expectation, this increases his profit. This is the case if $f \geq 1-\phi^{F C}\left(1-c_{I}\right)$, i.e. if the forward price is at least as great as the fair "insurance price". For the main buyer to accept such a contract, it should increase his utility. As taking an additional forward contract "over-insures" the main buyer (and hence is risky for him), he will only do so if the price is strictly lower than the fair "insurance price". Hence, the incumbent and the buyer will not be able to sign a contract which is profitable to both of them.

In stage 1, financial investors, anticipating that their deal is not threatened by the possibility for the incumbent subsequently to offer a forward contract, will sell insurance to the main buyer at the fair insurance price. In stage 2, the main buyer will accept the forward contract of the financial investors as it guarantees a utility of

$$
U\left(\left(c_{I}-k\right)\left(1-c_{I}\right)\right)>V^{N C}
$$

Entry will be efficient. 


\section{Discussion}

\subsection{Normative implications}

Table 1 summarizes the results of section 3. It describes for the three kinds of contractual relationships - no contract (NC), exclusivity contract (EC), and forward contract (FC) whether the financial market will develop (i.e. whether financial investors play an active role in equilibrium), whether the main buyer is insured, and whether entry in the market is efficient.

\begin{tabular}{|c|c||c|c|c|}
\hline Scenario & $\begin{array}{c}\text { Contracts that the } \\
\text { incumbent is allowed } \\
\text { to sign }\end{array}$ & $\begin{array}{c}\text { Financial } \\
\text { market } \\
\text { develops? }\end{array}$ & $\begin{array}{c}\text { Main } \\
\text { Buyer is } \\
\text { insured? }\end{array}$ & $\begin{array}{c}\text { Efficient } \\
\text { Entry? }\end{array}$ \\
\hline NC & $\begin{array}{c}\text { None } \\
\text { EC }\end{array}$ & Yes & Yes & Yes \\
FC & Forward Contract & Yes & Yes & Yo \\
\hline
\end{tabular}

Table 1 Market Outcome in the three scenarios

The main buyer will be insured in all scenarios, whether by buying forward contract from financial investors, or by signing an exclusivity contract with the incumbent. Entry is efficient as long as the incumbent is not allowed to use exclusive contracts. If exclusive contracts are allowed, then there is too little entry. Financial markets will only develop if the incumbent is not allowed to sign an exclusivity contract.

\begin{tabular}{|c|c|c||c|c||c|c|c|}
\hline \hline Scenario & \multirow{2}{*}{$\begin{array}{c}\text { Financial } \\
\text { investors } \\
\text { present? }\end{array}$} & $\begin{array}{c}\text { Contracts that the } \\
\text { incumbent is } \\
\text { allowed to sign }\end{array}$ & \multicolumn{2}{|c||}{ Risk sharing } & \multicolumn{2}{|c|}{ Entry } & $\begin{array}{c}\text { Total } \\
\text { Surplus }\end{array}$ \\
\cline { 4 - 8 } & Main buyer & Incumbent & Incumbent & Entrant & \\
\hline Benchmark & No & None & 0 & 0 & 0 & 0 & 0 \\
NC & Yes & None & $*$ & 0 & 0 & 0 & $*$ \\
EC & Yes & Exclusive Contract & 0 & $*$ & + & - & $*$ \\
FC & Yes & Financial Contract & $*$ & 0 & 0 & 0 & $*$ \\
\hline
\end{tabular}

* surplus created by hedging the risk of the main buyer

+ positive change in surplus associated to entry distortion

-- negative change in surplus associated to entry distortion

Table 2: Surplus of Main Buyer, Incumbent and Entrant in the three scenarios

Table 2 presents the utility levels of the main buyer, the incumbent and the entrant. Utilities levels are normalized with respect to a benchmark scenario where neither the financial investors nor the incumbent can offer contracts to the entrant. The utility levels of the players are affected by the development of financial markets (column 3 in Table 1) and by 
the entry decisions (column 5 in Table 1). Table 2 disentangles the utility effects of those two factors.

Gains from insuring the main buyer accrue entirely either to him or to the incumbent (the financial market, when it develops, is competitive and all gains accrue to the main buyer) and they are denoted by a star. Distorting entry by forcing the entrant to price low benefits the incumbent (plus sign) but penalizes the entrant to a greater extent (two minus signs). Changes in the grand sum of utilities are found by adding all effects.

We first discuss the effects for the main buyer. As long as the financial market does not develop, the incumbent has all the bargaining power vis-à-vis the main buyer. He will keep the main buyer at his reservation utility level. Hence, the main buyer's utility the exclusivity contract scenario (EC) is identical in the benchmark scenario without contracts. If the financial market develops, the incumbent loses his dominant position in the insurance market, and the main buyer will buy a forward contract from financial investors at the competitive rate. The surplus of the main buyer will therefore increase in scenarios NC and FC.

Entry is efficient in all scenarios, except in the EC scenario. In this latter scenario the entrant obtains a lower profit. She is indifferent between all other scenarios (benchmark, FC and NC) since entry is unaffected.

The profit of the incumbent depends on two parts. First, by restricting entry, the incumbent can extract rents from the entrant. The profit of the incumbent thus increases under scenario EC. Second, selling insurance to the main buyer is profitable for the incumbent if he is the sole seller of forward contracts. He then has monopoly power in the insurance market. He obtains this monopoly profit in the insurance market only in the EC scenario. In the other scenarios (benchmark, NC and FC) the incumbent does not sign a contract with the main buyer, and he earns his lowest profit.

We now compare the various scenarios from the point of view of the sum of utilities (last column in Table 2). Efficiency requires that the main buyer be insured and entry efficient. In all cases, the main buyer ends up being insured; only the distribution of gains from risk sharing is affected. In contrast, the use of exclusivity contracts allows the incumbent 
inefficiently to deter entry. Thus, scenario NC and scenario FC are equivalent and welfaredominate scenario EC in the presence of financial investors.

\subsection{In the absence of financial investors}

It is possible that financial markets do not develop for reasons that are unrelated to the moral hazard problem we identify in this paper. Liquidity is an issue: with a limited number of buyers in the industry, there may be few agents interested in trading derivatives. Table 3 summarizes how the conclusions of our analysis are affected by the absence of financial investors. ${ }^{14}$

\begin{tabular}{|c|c||c|c|}
\hline Scenario & $\begin{array}{c}\text { Contracts that the } \\
\text { incumbent is } \\
\text { allowed } \\
\text { to sign }\end{array}$ & $\begin{array}{c}\text { Main } \\
\text { Buyer is } \\
\text { insured? }\end{array}$ & $\begin{array}{c}\text { Efficient } \\
\text { Entry? }\end{array}$ \\
\hline $\begin{array}{c}\text { NC } \\
\text { (benchmark) }\end{array}$ & None & No & Yes \\
EC & Exclusive Contract & Yes & No \\
FC & Financial Contract & Yes & Yes \\
\hline
\end{tabular}

Table 3 Summary of the three scenarios in the absence of financial investors

In this context, scenario NC actually corresponds to the benchmark we considered in Table 2. As long as the incumbent is able to contract with the main buyer, the latter ends-up insured against price volatility. Scenario EC distorts entry, whereas the use of a forward contract (or the absence of contract) does not distort the product market outcome.

Table 4 compares the utility levels of the various scenarios. The main buyer achieves the same utility level in each scenario because the incumbent has all bargaining power, and holds him at his reservation utility. The incumbent, as long as he can contract with the main buyer, captures the gains from risk sharing (as financial investors are absent there is no competitive pressure on the incumbent in providing insurance). In addition he can extract some rents from the entrant by using an exclusivity contract to force low post-entry prices. Thus, he makes the most profit in scenario EC.

${ }_{14}$ They can be derived from the analysis in section 3, by looking at the subgames in which the main buyer has not previously bought a forward contract from financial investors. 
Scenario FC Pareto-dominates the NC outcome, as the surpluses of the main buyer and the entrant remain constant, while the profit of the incumbent increases. Allowing a financial contract improves risk sharing between the entrant and the incumbent, without restricting entry.

\begin{tabular}{|c|c|c|c|c|c|c|}
\hline \hline Scenario & \multirow{2}{*}{$\begin{array}{c}\text { Contracts that the } \\
\text { incumbent is } \\
\text { allowed to sign }\end{array}$} & \multicolumn{2}{|c|}{ Risk sharing } & \multicolumn{2}{c|}{ Entry } & $\begin{array}{c}\text { Total } \\
\text { Surplus }\end{array}$ \\
\cline { 3 - 7 } & & $\begin{array}{c}\text { Main } \\
\text { buyer }\end{array}$ & Incumbent & Incumbent & Entrant & \\
\hline $\begin{array}{c}\text { NC } \\
\text { (benchmark) }\end{array}$ & None & 0 & 0 & 0 & 0 & 0 \\
EC & Exclusive Contract & 0 & $*$ & + & -- & $*$ \\
FC & Financial Contract & 0 & $*$ & 0 & 0 & $*$ \\
\hline
\end{tabular}

* surplus created by hedging the risk of the main buyer

+ positive change in surplus associated to entry distortion

-- negative change in surplus associated to entry distortion

Table 4: Surplus of Main Buyer, Incumbent and Entrant in the absence of financial investors

If we replace the financial contract (FC) with an exclusivity contract (EC), then the profit of the incumbent goes up, the entrant is worse off and the main buyer remains at his reservation utility.

Comparing exclusive contract and the no-contract scenario (EC vs NC), we identify the following trade-off: with the exclusive contract, entry is inefficient, but the main buyer is insured. Which of the two effects dominates depends on the risk aversion of the main buyer. If the main buyer is very risk-averse, then the value of eliminating price risk is very high and may more than compensate for the inefficient entry profile associated to exclusivity.

\subsection{Policy implications}

Often, an incumbent firm and a buyer will sign an exclusivity contract. If this contract is questioned by antitrust authorities, the parties will typically present an efficiency defense running along the following lines:

(1) The future price of the good is uncertain, and the buyer is risk-averse. Hence the buyer would like to sign a contract to hedge his risk.

(2) A financial market does not exist in the sector; hence, the buyer needs to turn to the incumbent as a counterparty in a trade to reduce his risk 
Our model shows that if the incumbent can choose which contract to offer the main buyer, then he will go for an exclusivity contract. This contract will insure the buyer against variations in the spot price. Financial investors will not be willing to offer insurance to the buyer, and financial markets will not develop. If the buyer is very risk-averse, this outcome may socially be preferred to a situation without contracts. Hence, the arguments of the parties are seemingly correct.

However, it does not follow that insuring the buyer should be allowed as an efficiency defense for using exclusivity contracts. Those contracts not only foreclose the product market but also hinder the development of financial markets, which could provide alternative means for the buyer to hedge his risk. They are the cause of the very problem they allegedly solve!

Of course, other causes can explain why financial markets do not to develop. Even in those situations where alternative insurance providers are unavailable, insurance should not be allowed as an efficiency defense for exclusivity clause. The use of a simple forward contract socially dominates exclusive dealing, as it hedges the buyer without distorting entry. Such a forward contract does not require a financial market to exist, and can be signed between the buyer and the incumbent as long as there exists a well-functioning spot market, upon whose price to base the contract.

We therefore conclude that there is no room for an insurance defense of exclusionary exclusive dealing arrangements.

\subsection{Qualifications}

Following Aghion and Bolton (1987), we have made strong assumptions about market structure and interaction. Some of those assumptions are innocuous. For instance, we have taken the incumbent to be risk-neutral. If he were risk-averse, the results would not be affected because with either an exclusivity contract or a financial contract, all solutions involve mutual hedging of the parties, while in the absence of contract there is nothing that the incumbent can do to affect his level of risk. 
Similarly, for simplicity, we have taken the distribution of costs to be uniform. However, Propositions 1 and 2 remain valid for any (differentiable) cumulative distribution for which $\operatorname{Prob}\left(\mathrm{c}_{E}<\mathrm{c}_{I}\right)>0 .{ }^{15}$

Besides, in our model, absent an exclusivity contract, the post-entry price in the spot market is equal to the marginal cost of the incumbent. Fierce competition drives down the price to the point where the incumbent is no longer making a profit. If competition were less fierce, the post-entry price could be higher, and we could then obtain too much entry in the market.

We have assumed that the "fringe buyer" is very small. The presence of a large fringe buyer creates additional contracting externalities. In relative terms, this makes exclusion cheaper for the incumbent as he will be able to extract rents not only from the entrant, but also from the fringe buyer. As a result, deadweight loss will further increase. At the same time, coordination problems arise. A detailed discussion of these effects is outside the scope of the paper.

In the case of the financial contract we assumed that main buyer and the incumbent signed a financial contract that fully hedged their positions, i.e. they signed a forward contract for exactly one unit of output. In Argenton and Willems (2008), we show that the incumbent may be able to exclude the entrant if he sells more financial contracts than the amount of contracts that fully hedges his position. In other words, the incumbent can achieve entry deterrence if he speculates. Hence, our conclusion that exclusivity contracts should not be used to improve risk-sharing does not imply that there is no problem with purely financial contracts.

\section{Conclusion}

This paper revisited the seminal Aghion and Bolton (1987) model by introducing riskaversion on the part of the buyer, leaving some room for financial markets to develop, and allowing for a richer contracting environment. We have shown that exclusivity contracts,

\footnotetext{
${ }^{15}$ With a general cdf $F\left(c_{E}\right)$, relaxed program Error! Reference source not found. becomes (ignoring the fringe buyer and the cost of entry): $\max _{0 \leq p \leq 1}\left(1-c_{I}\right)+F(p)\left(1-c_{I}\right)$, which still leads to a corner solution if $\exists x \in\left[0, c_{I}\right]$ such that $F^{\prime}(x)>0$.
} 
although useful in hedging a risk-averse buyer, are instrumental in allowing the incumbent to exclude its rivals both on the product market and the financial market. Even in the absence of financial investors, a simple forward contract can take care of insuring consumers without distorting entry. So, there appears to be no room for an insurance justification for using exclusivity contracts whenever direct financial arrangements are possible. On the contrary, we have shown that an incumbent would always prefer to offer an exclusivity contract, as this contract allows him to extract more surplus from the buyer and the potential entrant. This comes at the cost of preventing financial markets from developing. We therefore conclude that by allowing an insurance defense of exclusivity contracts, policy-makers would run the risk of favoring anti-competitive incumbents at great cost to both the real and the financial sides of the economy.

\section{References}

Allaz, B. and Vila, J. L. (1993). "Cournot Competition, Forward Markets and Efficiency." Journal of Economic Theory, 59, 1-16.

Aghion, Philippe and Patrick Bolton (1987). "Contracts as a barrier to entry." American Economic Review, 77, 388-401.

Argenton, Cédric (2008). “Exclusive quality.” CentER discussion paper No. 2008-20.

Argenton, Cédric and Bert Willems (2008). "Exclusion through speculation." Mimeo, Tilburg University.

Berkman, H. and M. Bradbury (1996). "Empirical evidence on the corporate use of derivatives." Financial Management, 25(2), 5-13.

Bernheim, Douglas and Michael Whinston (1999). Anticompetitive exclusion and foreclosure through vertical agreements. Louvain: CORE Lecture series.

Besanko, D. and M.K. Perry (1993). "Equilibrium incentives for exclusive dealing in a differentiated products oligopoly." Rand Journal of Economics, 24, 646-667.

Brodley, Joseph F. and Ching-to Albert Ma (1993). "Contract penalties, monopolizing strategies and antitrust policy." Stanford Law Review, 45, 1161-1213.

Chew, Donald H. (ed.) (2007). Corporate risk management. New York: Columbia University Press.

De Meza, David and Mariano Selvaggi (2007). "Exclusive-contracts foster relation-specific investment." Rand Journal of Economics, 38, 85-97.

Fumagalli, Chiara, Massimo Motta and Thomas Rønde (2008). "Exclusive dealing: the interaction between foreclosure and investment promotion." Mimeo.

Gézci, Christopher, Bernadette A. Minton and Catherine Schrand (1997). "Why firms use currency derivatives." Journal of Finance, 52(4), 1323-1354. 
Graham, John R. and Daniel A. Rogers (2002). "Do firms hedge in response to tax incentives?" Journal of Finance, 57, 815-839.

Guay, Wayne and S.P. Kothari (2003). "How much do firms hedge with derivatives?" Journal of Financial Economics, 70, 423-461.

Haushalter, G. (2000). "Financing policy, basis risk, and corporate hedging: evidence from oil and gas producers." Journal of Finance, 55, 107-152.

Mahenc, P. and Salanié, F. (2004). "Softening Competition Through Forward Trading." Journal of Economic Theory, 116(2), 282-293.

Mathewson, F. and R. Winter (1984). "An economic theory of vertical restraints." Rand Journal of Economics, 15, 27-38.

Mian, S. (1996). "Evidence on corporate hedging policy." Journal of Financial and Quantitative Analysis, 31, 419-439.

Nance, D., C. Smith, and C. Smithson (1993). "On the determinants of corporate hedging." Journal of Finance, 48, 267-284.

Rasmusen, Eric B., J. Mark Ramseyer and John S. Wiley (1991). "Naked exclusion." American Economic Review, 81, 1137-1145.

Rey, Patrick and Jean Tirole (1986). "The logic of vertical restraints." American Economic Review, 76, 921-939.

Rey, Patrick and Jean Tirole (2006). "A primer on foreclosure." In Mark Armstrong and Rob Porter (eds), Handbook of Industrial Organization, vol. 3, Amsterdam: North-Holland, 2145-2220.

Segal, Ilya R. and Michael D. Whinston (2000a). "Naked exclusion: comment." American Economic Review, 90, 296-309.

Segal, Ilya R. and Michael D. Whinston (2000b). "Exclusive contracts and protection of investments." Rand Journal of Economics, 31, 603-633.

Spier, Kathryn E. and Michael D. Whinston (1995). “On the efficiency of privately stipulated damages for breach of contract: entry barriers, reliance, and renegotiation." Rand Journal of Economics, 26, 180-202.

Spiegel, Yossi (1994). "On the economic efficiency of liquidated damages." Economics Letters, 45, 379-383.

Willems, Bert (2005). "Physical and Financial Virtual Power Plants" K.U.Leuven CES working paper No. 0512.

Willems, Bert and Emmanuel de Corte (2008). "Market power mitigation by regulating contract portfolio risk." Energy Policy, 36(10), 3787-3796.

Wolak, Frank and Charles D. Kolstad (1991). "A model of homogeneous input demand under price uncertainty." American Economic Review, 81(3), 514-538.

Yehezkel, Yaron (2008). "Retailers' choice of product variety and exclusive dealing under asymmetric information." Rand Journal of Economics, 29, 115-143. 